\title{
Histopathology of ethmoid mucosa versus polyp tissue in diagnosing eosinophilic mucin rhinosinusitis*
}

\section{Wanrawee Thaitrakool ${ }^{1,2}$, Narittee Sukswai ${ }^{3}$, Somboon Keelawat ${ }^{3}$, Supinda Chusakul ${ }^{1,2}$, Jesada Kanjanaumporn 1,2, Songklot Aeumjaturapat ${ }^{1,2}$, Kornkiat Snidvongs ${ }^{1,2}$}

Rhinology 57: 1, $67-72,2019$

https://doi.org/10.4193/Rhin18.068

*Received for publication:

MArch 30, 2018

Accepted: November 18, 2018

2 Endoscopic Nasal and Sinus Surgery Excellence Center, King Chulalongkorn Memorial Hospital, Bangkok, Thailand

${ }^{3}$ Department of Pathology, Faculty of Medicine, Chulalongkorn University, Bangkok, Thailand

Background: This study aims to compare histopathology of nasal polyp and ethmoid mucosa for diagnosing eosinophilic mucin rhinosinusitis (EMRS).

Methodology: Patients with chronic rhinosinusitis with polyps (CRSwNP) were enrolled. Using eosinophilic mucin as a reference, histopathology of polyp apex, polyp pedicle and ethmoid mucosa was compared for density of tissue eosinophil and sensitivity for diagnosing EMRS. Associations with asthma were assessed for each site.

Results: Thirty patients with CRSwNP were enrolled. When polyp apex, polyp pedicle and ethmoid mucosa were assessed for tissue eosinophilia, consistent results were reported in 16 patients (53\%). Median tissue eosinophil was greater in polyp apex (58, IQR: 7-100) than ethmoid mucosa (10, IQR: 2-21), but not different from polyp pedicle (22, IQR: 1-96). Sensitivity for diagnosing EMRS were 100\% (95\%Cl: 47.8 - 100) for polyp apex, 60\% (95\%Cl: 14.7 - 94.7) for polyp pedicle, 80\% (95\%Cl: 28.4 - 99.5$)$ for ethmoid mucosa. Associations with asthma were significant for polyp pedicle, and ethmoid mucosa but not polyp apex.

Conclusion: Density of tissue eosinophil was greater in nasal polyp than in ethmoid mucosa. Histopathology of polyp apex had good sensitivity for diagnosing EMRS. Polyp pedicle and ethmoid mucosal eosinophilia associated with asthma.

Key words: sinusitis, ethmoid sinus, nasal polyps, nasal mucosa, histology

\section{Introduction}

Chronic rhinosinusitis (CRS) is a heterogenous disease with various etiologies and several predisposing factors ${ }^{(1)}$. Both dysregulation of the individual host and multi-factors exogenous to the host have been hypothesized ${ }^{(2)}$. Histopathological examination of CRS is therefore an essential step in determining pathogenesis. Non-eosinophilic CRS ( $\mathrm{nECRS)}$ is related with T-helper1 and T-helper17 pathways while eosinophilic inflammation appears to favor T-helper 2 mediated inflammation. Eosinophilic mucin rhinosinusitis (EMRS) is a subtype of CRS with a systemic dysregulation related with upper and lower airway eosinophi$\mathrm{lia}^{(3)}$. Histopathological characteristics of its mucin demonstrate eosinophils, eosinophil aggregates, and the by-product of eosinophils, Charcot-Leyden crystals. Eosinophils release toxic proteins including major basic protein and eosinophil cationic protein. These toxic proteins intoxicate nasal mucosa and sur- rounding tissues. In addition, they are associated with airway hyperactivity, vascular leakage, mucus secretion overproduction, epithelial injury, tissue remodeling factors and large production of cytokines including interleukin 4, interleukin 5, leukotrienes and eotaxin ${ }^{(4,5)}$.

Phenotypic features are commonly used for predicting the underlying inflammatory process of CRS which suggests individualized effective therapeutic options. Presence of nasal polyp and viscous eosinophilic mucin (eosinophils aggregation with Charcot-Leyden crystals) $)^{(3,6-9)}$, are manifestations of eosinophil activation in EMRS ${ }^{(10-12)}$. However, phenotypic features are not accurate for diagnosing EMRS as high tissue eosinophilia can be found in patients with CRS without polyps (CRSsNP) with a percentage of $19 \%^{(11)}$. CRS with polyps (CRSwNP), although related with eosinophilic inflammation, may present with diverse inflammatory patterns ${ }^{(13)}$. Therefore, compared to CRS pheno- 
types, histopathological assessment of high tissue eosinophilia should be more reliable. However, there is no consensus yet regarding an appropriate source of tissue taken for histopathologic assessment. Tissue from various locations have been studied to assess tissue eosinophil count. While several researchers studied polyp tissue ${ }^{(10,14-19)}$, others studied ethmoid mucosa ${ }^{(11,12,}$ ${ }^{20-22)}$. Different sources for tissue biopsies have different density of inflammatory cell infiltration. This should affect number of tissue eosinophil reported as well as, the sensitivity and specificity for evaluating CRS endotypes.

This study aimed to assess histopathology of three sources of tissue; polyp apex, polyp pedicle and ethmoid mucosa to see whether the findings of high tissue eosinophilia were intrapersonal consistent and to compare these three locations on density of tissue eosinophils and its sensitivity and specificity on diagnosing EMRS by using eosinophilic mucin as a reference. In addition, this study aimed to see which locations showed significant association with comorbid asthma.

\section{Material and Methods}

This study was approved by the Institutional Review Board of the Faculty of Medicine, Chulalongkorn University number 560/58. We screened patients with CRSwNP who presented at the Endoscopic Nasal and Sinus Surgery Excellence Center, King Chulalongkorn Memorial Hospital from January 2016 to January 2017. In this study, high tissue eosinophilia was defined when all three sites of polyp apex, polyp pedicle and ethmoid mucosa reported tissue eosinophils greater than 10/HPF ${ }^{(11,20)}$. Eosinophilic mucin was histopathologically defined when the mucin demonstrated eosinophils, eosinophil aggregates, and the by-product of eosinophils, Charcot-Leyden crystals ${ }^{(3)}$. Serum eosinophilia was defined as an increase in peripheral blood eosinophilic leukocytes to either greater than $6 \%$ or more than 600 cells per microliter $(\mu \mathrm{L})$ of blood.

\section{Patient population}

Patients with bilateral CRSwNP, scheduled for endoscopic sinus surgery were enrolled. The diagnosis of CRSwNP was based on history, clinical examination, nasal endoscopy, and computed tomographic scanning of the sinuses. All patients fulfilled the criteria of bilateral nasal polyps according to the European Position Paper on Rhinosinusitis and Nasal Polyps (EPOS 2012) (1). All patients signed informed consents before participation in the study. Patients taking antibiotics, topical corticosteroids or systemic corticosteroids within 4 weeks before endoscopic sinus surgery were excluded. Other exclusion criteria were cystic fibrosis, immunodeficiency, primary ciliary dyskinesia, fungal rhinosinusitis, systemic vasculitis and granulomatous diseases, cocaine abuse, and neoplasia. Comorbidity of asthma was recorded if present; defined as clinically using inhaled $\beta$-agonist or corticosteroids. Preoperative Lund-Kennedy endoscopy score and Lund-Mackay CT score were recorded.

\section{Histopathology assessment}

To assess inflammatory pattern of CRSwNP, antibiotics, or corticosteroids were not allowed. Tissue specimens were collected intra-operatively from three sources; polyp apex, polyp pedicle and ethmoid mucosa. Polyp apex was defined as the top part of nasal polyps exposed to the airflow. Polyp pedicle was defined as the part of nasal polyps attached to the underlying bone. Ethmoid mucosa was taken from the bulla ethmoidalis. All studied tissues were processed using a standard pathological laboratory technique. The studied tissues were fixed and processed for tissue paraffin embedding. Paraffin embedded tissues were sectioned at $5 \mu \mathrm{m}$ thickness, processed by hematoxylin/ eosin staining and then collected in the slides bank for histopathological review. This was assessed by a single certified pathologist in a blind fashion, where the pathologist knew neither patient history, and characteristics nor the source of tissue specimens. All studied slides were evaluated for histopathology profiling described in a published study ${ }^{(11)}$. The absolute number of tissue eosinophil was counted in all three sources of tissue. Low power microscopic magnification was used to scan and to identify three non-overlapping most intense areas of inflammatory cell infiltration. These three areas were then assessed by bright-field light microscopy at $\times 400$ magnification. Tissue eosinophils were counted as numbers of eosinophils per HPF in three areas and the median of eosinophil counts was used. High tissue eosinophilia was defined when the median of eosinophil counts was $\geq 10 /$ HPF. Histopathological data were recorded ${ }^{(11)}$ for each source of the studied tissues (polyp apex, polyp pedicle and ethmoid mucosa). Mucin was collected in formalin or fixed immediately onto slide with $95 \%$ alcohol if of small quantity. The slides were stained with hematoxylin-eosin for evaluation of inflammatory pattern and with Gomeri methenamine-silver stain for identification of fungal hyphae. Mucin was evaluated by bright-field light microscopy at $\times 400$ magnification for presence or absence of eosinophil aggregates, Charcot-Leyden crystals and fungal elements.

\section{Statistical analysis}

Descriptive data were presented as means \pm standard deviation (SD), median \pm interquartile range (IQR) and percentages. Friedman and Wilcoxon sign rank test were used for comparing different non-parametric variables. McNemar test was used to assess diagnostic ability of each location. Receiver operation characteristic curve (ROC curve) was used to evaluate ability of tissue eosinophilia from ethmoid mucosa and polyp tissue in diagnosing EMRS. Chi squared analysis was used for relationships of nominal variables. The $P$ value of $\leq 0.05$ was defined as statistical significance. Statistical analyses were performed using STATA version 15.0 (Stata Corp., TX, USA) 


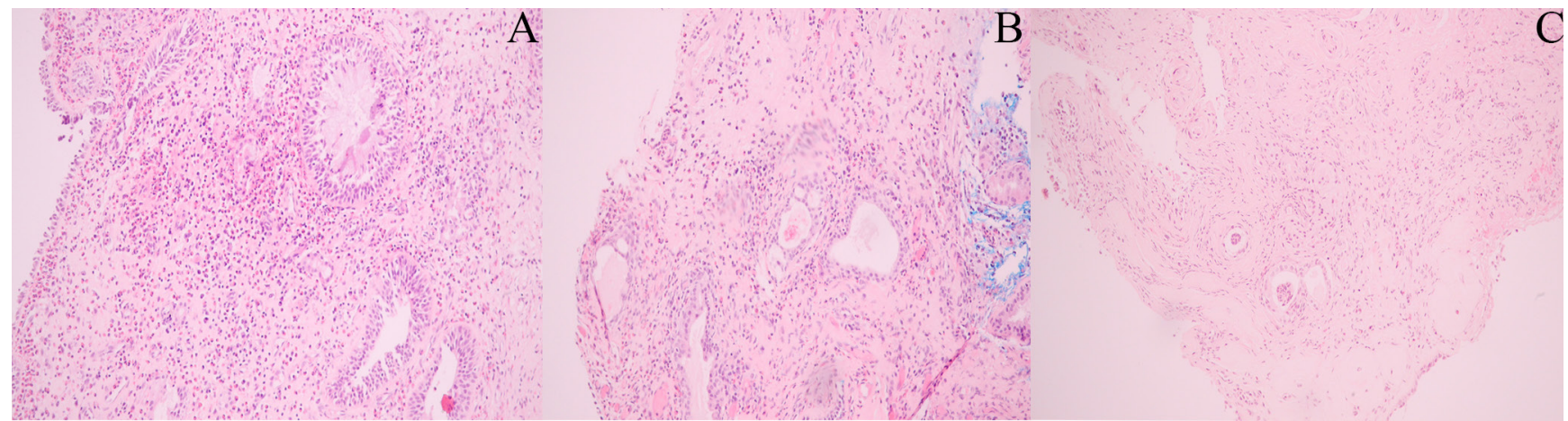

Figure 1. Difference in tissue eosinophil count among three sites of tissue sample: polyp apex (A), polyp pedicle (B) and ethmoid mucosa (C).

\section{Results}

Thirty patients with a mean age of $48.6 \pm 16.7$ years old were enrolled. Seventeen (57\%) patients were male. Nine (30\%) patients were asthmatic. Five (17\%) patients had received previous endoscopic sinus surgery. Four (13\%) patients had serum eosinophilia. Median percentage of eosinophil in the serum was 5\% (1.6 - 7.6). Median Lund-Kennedy endoscopy score was 11 (7 - 12). Median Lund-Mackay CT scan score was 18 (14 - 21). When tissue eosinophilia was assessed from polyp apex, polyp pedicle and ethmoid mucosa, the three sites showed consistent findings in sixteen (53\%) patients. Eleven (37\%) patients had high tissue eosinophilia consistently. Five (17\%) patients had non-eosinophilic inflammation consistently and were diagnosed as nECRS.

\section{Density of tissue eosinophil by sources of tissue specimens} Figure 1 displays intrapersonal difference in tissue eosinophil count among three sites of tissue sample. Tissue eosinophil count from polyp apex (median 58, IQR 7-100) was significantly greater than from ethmoid mucosa (median 10, IQR 2-21), $\mathrm{p}=0.03$. Density of tissue eosinophil in polyp pedicle (median 22, IQR 1-96) was not statistically different from ethmoid mucosa $(p=0.10)$ and polyp apex ( $p=0.59)$. For multiple comparison, there was no significant difference $(p=0.11$ ) among polyp apex, polyp pedicle and ethmoid mucosa. Figure 2 displays dot plots showing number of tissue eosinophil by sources of tissue specimens. Each dot represents individual patient.
Assessment of each source of tissue specimens for diagnosing EMRS

Using presence of eosinophilic mucin (Figure 3) as a reference for diagnosing EMRS, polyp apex had sensitivity of $100 \%$ (95\% Cl: 47.8 - 100), specificity of $36 \%$ (95\%Cl: $18-57.5)$, positive predictive value of $23.8 \%$ (95\% Cl: 8.2-47.2) and negative predictive value of $100 \%$ (95\%Cl: $66.4-100)$. The area under the curve of ROC was 0.68 (95\%Cl: 0.58-0.78). Youden index was 0.36 . Polyp pedicle had sensitivity of $60 \%$ (95\%Cl: 14.7 - 94.7), specificity of $40 \%$ (95\%Cl: $21.1-61.3)$, positive predictive value of $16.7 \%$ (95\%Cl: 3.6-41.4) and negative predictive value of $83.3 \%$ (95\%Cl: $51.6-97.9$ ). The area under the curve of ROC was 0.5 (95\%Cl: 0.24-0.76). Youden index was 0.

Ethmoid mucosa had sensitivity of $80 \%$ (95\%Cl: $28.4-99.5)$, specificity of $48 \%$ ( $95 \% \mathrm{Cl}: 27.8-68.7)$, positive predictive value of $23.5 \%$ (95\%Cl: $6.8-49.9)$ and negative predictive value of $92.3 \%$ (95\%Cl: 64-99.8). The area under the curve of ROC was 0.64 (95\%Cl: 0.42-0.86). Youden index was 0.28 .

Assessment of each source of tissue specimens for association with asthma

An association between high tissue eosinophilia and comorbid asthma was revealed when histopathology was assessed from polyp pedicle and ethmoid mucosa. This association was not seen when polyp apex was studied. Data are displayed in Table 1.

Table 1. Performance of each source of tissue specimens on association with comorbid asthma.

\begin{tabular}{|c|c|c|c|c|c|}
\hline & & Asthma n (\%) & No asthma $n(\%)$ & Total n (\%) & p-value \\
\hline \multirow[t]{2}{*}{ Polyp apex } & High tissue eosinophilia & $8(26.7)$ & $13(43.3)$ & $21(70.0)$ & \multirow[t]{2}{*}{0.21} \\
\hline & nECRS & $1(3.3)$ & $8(26.7)$ & $9(30.0)$ & \\
\hline \multirow[t]{2}{*}{ Polyp pedicle } & High tissue eosinophilia & $8(26.7)$ & $10(33.3)$ & $18(60.0)$ & \multirow[t]{2}{*}{0.05} \\
\hline & nECRS & $1(3.3)$ & $11(36.7)$ & $12(40.0)$ & \\
\hline \multirow[t]{2}{*}{ Ethmoid mucosa } & High tissue eosinophilia & $8(26.7)$ & $9(30.0)$ & $17(56.7)$ & \multirow[t]{2}{*}{0.04} \\
\hline & $\mathrm{nECRS}$ & $1(3.3)$ & $12(40.0)$ & $13(43.3)$ & \\
\hline
\end{tabular}




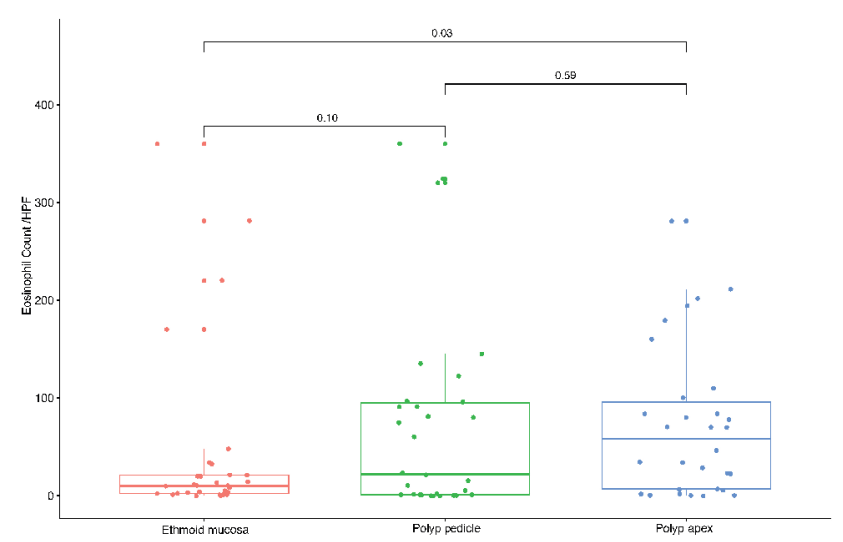

Figure 2. Dot plots of number of tissue eosinophil by sources of tissue specimens. Each dot represents individual patient. HPF: high power field, blue dot: polyp apex, green dot: polyp pedicle and orange dot: ethmoid mucosa.

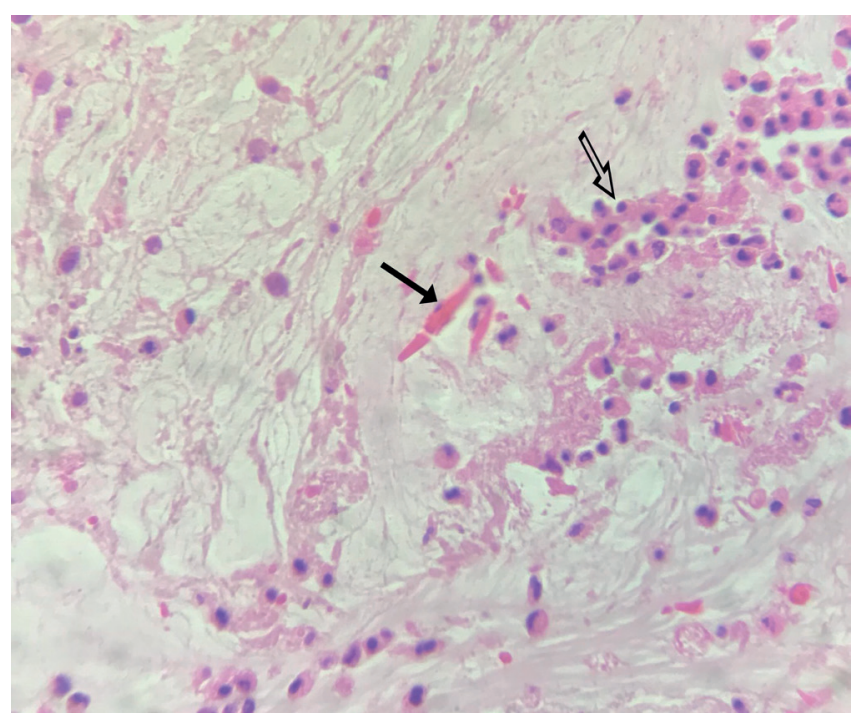

Figure 3. Histopathology of eosinophilic mucin showing eosinophils (white arrow) and Charcot-Leyden crystals (black arrow).

\section{Discussion}

Nasal polyps are mucosal sac composed of edematous tissue, fibrous tissue, blood vessels, inflammatory cells and glands. The covered pseudostratified columnar cylindric epithelium and inflammatory cells of nasal polyps change during their growth and development ${ }^{(23)}$. Our study shows that density of tissue eosinophilia was greater in nasal polyps than ethmoid mucosa. Histopathology assessed from polyp apex had greater sensitivity for diagnosing EMRS than from polyp pedicles and ethmoid mucosa and its negative predictive value is $100 \%$. This may be an effect of air current flow on the polyp apex resulting in further histopathological change which explains these findings. Therefore, the polyp apex should be a sensitive site to define inflammatory patterns of chronic inflammatory disease of paranasal sinuses. Nasal polyp is simply one clinical feature of chronic inflammation other than a disease, so it well represents underlying inflammatory process of CRS. This is in line with a previous analytic study of serially-sectioned nasal polyps showing larger areas of transitional epithelium and lower goblet cell density in anterior polyp halves ${ }^{(23)}$. According to the work of Pawliczak et al. ${ }^{(24)}$, histopathology assessment of superficial layers of polyp apex was more accurate than stromal layers. They found that distribution of eosinophils and mast cells in nasal polyps are more abundant in superficial layers. In addition, the site of nasal polyps occurrence is more common in the area exposed to the air current flow such as the middle meatal mucosa, uncinate process, and infundibulum ${ }^{(23,25,26)}$. Ho et al. ${ }^{(27)}$ studied cellular comparison of polyp tissue versus sinus mucosa from a single sinus cavity in chronic rhinosinusitis. They found the elevation of ILC2s, activated CD8 ${ }^{+} T$ cells, pDCs, plasma cells and lgG ${ }^{+} B$ cells in nasal polyps when compared to sinus mucosa. They hypothe- sized that these cells are related with the developmental process of nasal polyps and they suggested nasal polyp tissue biopsy for investigation of CRS. The other study by Sasaki et al. ${ }^{(28)}$ found higher density of mast cells and degranulated mast cells in nasal polyp pedicle than in nasal polyp apex. Density of eosinophils which represents Th polarization of CRS was not assessed. Both polyp tissue ${ }^{(10,14-19)}$, and ethmoid mucosa $a^{(11,12,20-22)}$ were assessed for inflammatory pattern of CRS. Findings from this study showed that assessment of high tissue eosinophilia from different sources of tissue specimen gave similar reports in only about half of the patients. Histopathology assessment of different sources of tissue specimens may bring different findings and unreliable interpretation. For examples, two studies within the same country reported contradicting findings. When polyp tissue was assessed, Belgian polyp tissue showed eosinophilic inflammatory pattern ${ }^{(13)}$. However, when sinus mucosa specimens were obtained and assessed by the other Belgian group, up to forty percent of the patients had no eosinophilic inflammation of the mucosa ${ }^{(21)}$.

In this study, a bias on eosinophil count was reduced by an existing predetermined protocol(11) and use of a blinded single certified pathologist. Selecting areas for HPF counts, most histopathologists commonly assess most intense inflammatory areas. The median of eosinophil counts was used to reduce the bias that the distribution of eosinophils may not be homogenous. Eosinophilic mucin was used as a reference because it is an important character of EMRS. It demonstrates the eosinophil activation evidenced in $\mathrm{EMRS}^{(6)}$. Nasal exudates from the lateral nasal wall was assessed by Armengot et al. ${ }^{(10)}$. Eosinophilic inflammation found in the exudate had a strong relationship with the inflammatory pattern in the polyp tissue. 
Although polyp apex is sensitive to define EMRS, it does not associate with co-morbidity asthma. Instead we found an association when tissue eosinophilia was assessed from ethmoid mucosa and polyp pedicle. This is in agreement with a study of Weibman et al. ${ }^{(29)}$. They studied CRSwNP patients and found that eosinophilia in uncinate process tissue mucosa was a more coherent biomarker of co-morbidity asthma than eosinophilia in nasal polyp. These findings may support the hypothesis of one airway disease ${ }^{(30,31)}$ as ethmoid mucosa, and uncinate process have the same epithelial lining of respiratory epithelium with the lower airway.

Our findings should suggest an appropriate site of tissue specimens taken for histopathology. The greatest density of eosinophils in polyp apex suggests that it has high sensitivity and negative predictive value which is useful for screening purpose. However, its specificity is poor. In case that clinicians need more specific tools for selecting favorable patients for biomedicine, key cytokines and seromarkers should be assessed ${ }^{(32)}$. For examples, serum IgE should be assessed before prescribing omalizumab and serum IL-5 level should be assessed before prescribing reslizumab ${ }^{(33)}$. Histopathology assessment prior to surgery is helpful to predict further clinical severity, prognosis and therapeutic decision. Thus, polyp apex biopsy may be performed for screening purpose at the clinic without the need for endoscopic sinus surgery. Other options which might be easier include a curettage on the polyp apex and a collection of mucus. Histopathology assessment of polyp tissue scraping, and eosinophilic mucin are simple, and less invasive. Further studies are required.

\section{Conclusions}

Density of tissue eosinophil was greater in nasal polyp than ethmoid mucosa. Histopathology of polyp apex had good sensitivity for diagnosing EMRS. However, its specificity was poor. Number of tissue eosinophil in polyp pedicles and ethmoid mucosa better associated with comorbid asthma than polyp apexes. To assess histopathology of chronic rhinosinusitis with polyps, polyp apex biopsy at the clinic is useful for screening. Understanding the underlying inflammatory pattern should guide further treatment.

\section{Acknowledgements}

The authors wish to thank Ratchadapiseksompotch Research Fund for the financial support.

\section{Authorship contribution}

WT: Study design, Data collection, Data analysis, Manuscript preparation; NS, SK, SC, JK, SA: Data collection, Manuscript review; KS: Conception, Study design, Data analysis, Manuscript preparation, Final approval.

\section{Conflict of interest}

None of the authors has anything to disclose related to this manuscript.

\section{References}

1. Fokkens WJ, Lund VJ, Mullol J, Bachert C Alobid I, Baroody F, et al. EPOS 2012: European position paper on rhinosinusitis and nasal polyps 2012. A summary for otorhinolaryngologists. Rhinology 2012;50:1-12

2. Lam K, Schleimer R, Kern RC. The Etiology and Pathogenesis of Chronic Rhinosinusitis: a Review of Current Hypotheses. Curr Allergy Asthma Rep 2015;15:540.

3. Ferguson BJ. Eosinophilic mucin rhinosinusitis: a distinct clinicopathological entity. Laryngoscope. 2000;110:799-813.

4. Jones DG. The eosinophil. J Comp Pathol 1993;108:317-35.

5. Ferguson BJ. Categorization of eosinophilic chronic rhinosinusitis. Curr Opin Otolaryngol Head Neck Surg 2004;12:23742.

6. Barham HP, Osborn JL, Snidvongs K, Mrad N, Sacks R, Harvey RJ. Remodeling changes of the upper airway with chronic rhinosinusitis. Int Forum Allergy Rhinol 2015;5:565-72.

7. Vlaminck S, Vauterin T, Hellings PW, Jorissen $M$, Acke $F$, Van Cauwenberge $P$, et al. The importance of local eosinophilia in the surgical outcome of chronic rhinosinusitis: a 3-year prospective observational study. Am
J Rhinol Allergy 2014:28:260-4

8. Lee SH, Kim HJ, Lee JW, Yoon YH, Kim YM, Rha KS. Categorization and clinicopathological features of chronic rhinosinusitis with eosinophilic mucin in a korean population. Clin Exp Otorhinolaryngol 2015;8:39-45.

9. Uri N, Ronen O, Marshak T, Parpara O, Nashashibi M, Gruber M. Allergic fungal sinusitis and eosinophilic mucin rhinosinusitis: diagnostic criteria. J Laryngol Otol 2013;127:867-71.

10. Armengot M, Garin L, de Lamo M, Krause F, Carda C. Cytological and tissue eosinophilia correlations in nasal polyposis. Am J Rhinol Allergy 2010;24:413-5.

11. Snidvongs K, Lam M, Sacks $R$, et al. Structured histopathology profiling of chronic rhinosinusitis in routine practice. Int Forum Allergy Rhinol. 2012;2:376-85.

12. Soler ZM, Sauer DA, Mace J, Smith TL. Relationship between clinical measures and histopathologic findings in chronic rhinosinusitis. Otolaryngol Head Neck Surg 2009;141:454-61.

13. Zhang N, Van Zele T, Perez-Novo C, Van Bruaene N, Holtappels G, DeRuyck N, et al. Different types of T-effector cells orchestrate mucosal inflammation in chronic sinus disease. J Allergy Clin Immunol
2008;122:961-8

14. Bateman ND, Shahi A, Feeley KM, Woolford TJ. Activated eosinophils in nasal polyps: a comparison of asthmatic and non-asthmatic patients. Clin Otolaryngol 2005;30:221-5.

15. Lou H, Meng Y, Piao Y, Wang C, Zhang L, Bachert C. Predictive significance of tissue eosinophilia for nasal polyp recurrence in the Chinese population. Am J Rhinol Allergy 2015.

16. Grgic MV, Cupic H, Kalogjera L, Baudoin T. Surgical treatment for nasal polyposis: predictors of outcome. Eur Arch Otorhinolaryngol 2015.

17. Wen W, Liu W, Zhang L, Bai J, Fan Y, Xia W, et al. Increased neutrophilia in nasal polyps reduces the response to oral corticosteroid therapy. J Allergy Clin Immunol 2012;129:1522-8 e5.

18. Payne SC, Early SB, Huyett P, Han JK, Borish L, Steinke JW. Evidence for distinct histologic profile of nasal polyps with and without eosinophilia. Laryngoscope 2011;121:22627.

19. Kirtsreesakul V, Atchariyasathian V. Nasal polyposis: role of allergy on therapeutic response of eosinophil- and noneosinophil-dominated inflammation. Am J Rhinol 2006;20:95-100. 
20. Soler ZM, Sauer D, Mace J, Smith TL. Impact of mucosal eosinophilia and nasal polyposis on quality-of-life outcomes after sinus surgery. Otolaryngol Head Neck Surg 2010;142:64-71.

21. Szucs E, Ravandi S, Goossens A, Beel M, Clement PA. Eosinophilia in the ethmoid mucosa and its relationship to the severity of inflammation in chronic rhinosinusitis. Am J Rhinol 2002;16:131-4.

22. Cousin JN, Har-El G, Li J. Is there a correlation between radiographic and histologic findings in chronic sinusitis? J Otolaryngol 2000;29:170-3.

23. Mirko Tos, Larsen PL. Nasal Polyps: Origin, etiology, pathogenesis, and structure. In: David W. Kennedy, William E. Bolger, Zinreich SJ, editors. Diseases of the sinuses diagnosis and management. 1 ed. Hamilton London: B.C. Decker Inc.; 2001. p. 57-68.

24. Pawliczak R, Kowalski ML, Danilewicz M, Wagrowska-Danilewicz M, Lewandowski A. Distribution of mast cells and eosinophils in nasal polyps from atopic and nonatopic subjects: a morphometric study. Am J Rhinol 1997;11:257-62.

25. Stammberger H, Posawetz W. Functional endoscopic sinus surgery. Concept, indications and results of the Messerklinger technique. Eur Arch Otorhinolaryngol 1990;247:63-76

26. Benamara A, Nguyen DT, Boulanger N,
Arous F, Baumann C, Jankowski R. The site of origin of nasal polyposis in the ethmoid subcompartments assessed from clinical observation of ninety-four nasal cavities. Clin Otolaryngol 2013;38:402-6.

27. Ho J, Bailey M, Zaunders J, Mrad N, Sacks R, Sewell W, et al. Cellular comparison of sinus mucosa vs polyp tissue from a single sinus cavity in chronic rhinosinusitis. Int Forum Allergy Rhinol 2015;5:14-27.

28. Sasaki Y. Distribution of the degranulated and non-degranulated mast cells in nasal polyp. Acta Otolaryngol Suppl 1986;430:348.

29. Weibman AR, Huang JH, Stevens WW, Suh $L A$, Price CPE, Lidder AK, et al. A prospective analysis evaluating tissue biopsy location and its clinical relevance in chronic rhinosinusitis with nasal polyps. Int Forum Allergy Rhinol 2017;7:1058-64.

30. Hakansson K, Bachert C, Konge L, Thomsen SF, Pedersen AE, Poulsen SS, et al. Airway Inflammation in Chronic Rhinosinusitis with Nasal Polyps and Asthma: The United Airways Concept Further Supported. PLoS One 2015;10:e0127228.

31. Kariyawasam HH, Rotiroti G. Allergic rhinitis, chronic rhinosinusitis and asthma: unravelling a complex relationship. Curr Opin Otolaryngol Head Neck Surg 2013;21:79-86.

32. Tomassen P, Vandeplas G, Van Zele T, et al Inflammatory endotypes of chronic rhinosi- nusitis based on cluster analysis of biomarkers. J Allergy Clin Immunol. 2016;137:144956 e 4

33. Gevaert $P$, Lang-Loidolt D, Lackner A, et al. Nasal IL-5 levels determine the response to anti-IL-5 treatment in patients with nasal polyps. J Allergy Clin Immunol. 2006;118:1133-41.

Kornkiat Snidvongs

Endoscopic Nasal and Sinus Surgery

Excellence Center

King Chulalongkorn Memorial

Hospital

Department of Otolaryngology

Faculty of Medicine

Chulalongkorn University

Pathumwan

Bangkok10330

Thailand

Tel: +66-22564103

Fax: +66-2252 7787

E-mail: drkornkiat@yahoo.com 